\title{
Preocupações dos Cidadãos Portugueses sobre Biotecnologia na Agricultura Um Contributo para a sua Caracterização Mediante Focus Crupos
}

\author{
M. Alexandra Abreu Lima* \\ Lia T. Vasconcelos*
}

\begin{abstract}
$\mathrm{R}$
Resumo: Neste artigo avalia-se a percepção pública da biotecnologia na agricultura usando uma metodologia de "focus group" com participação de agricultores, de profissionais do meio rural e cientistas/peritos da I\&D agrícola. Através da análise do discurso interpretam-se as visões dos participantes, as suas preocupações sobre inovações e biotecnologia na agricultura, bem como os benefícios que delas advêm. Apresentam-se os resultados e discute-se a importância da participação pública alargada sobre este tema e modos pelos quais essas preocupações podem ser tomadas em consideração por investigadores e decisores políticos numa fase em que as medidas legislativas sobre coexistência entre culturas geneticamente modificadas e convencionais têm vindo a ser contestadas por sectores pró - OGM (CIB, 2005; CIB, 2006, cit. AgroPortal, 2006) e anti - OGM (PTFP, 2005; 2006) da sociedade Portuguesa.
\end{abstract}

Palavras-chave: Focus groups; Organismos geneticamente modificados (OGM); Território agrícola; Participação pública.

\section{Introdução}

$\mathrm{Na}$ "sociedade de risco" (Beck, 1992), um dos assuntos que tem suscitado anseios e preocupações nos cidadãos refere-se aos organismos geneticamente modificados (OGM). Neste domínio, resultante da pressão gerada por estes anseios, tem sido constatado no meio científico um equacionar de interpretações de diversa índole (éticas, sociais, entre outras) para além das de cariz estritamente científico. De facto, se por um lado verificamos que algumas inovações tecnológicas surgem como resultado de redes sociais que englobam uma diversa gama de actores sociais, incluindo utilizadores $^{1}$, por outro lado constatamos que a concepção de "ciência pós-normal" permite que a incerteza e a fidelidade aos valores influenciem as decisões sobre riscos (Borch and Rasmussen, 2005), pelo que "as necessárias alterações na comunidade científica que isto implica foram descritas como a transição (da produção de conhecimento) de 'Modo 1' para 'Modo 2"' (Gibbons, 1999; Gibbons et al., 1994; Nowotny et al., 2001) (cit. Borch and Rasmussen, 2005: p. 559).

Nesta medida, ao passo que a produção de conhecimento de 'Modo l' é gerada por uma discreta comunidade dedicada a uma dada área disciplinar e num contexto predominantemente cognitivo, a produção de conhecimento de 'Modo 2' surgirá em contextos sociais e económicos mais alargados e interdisciplinares (Borch and Rasmussen, 2005). Deste modo, a inclusão de actores sociais constitui uma das características do designado 'Modo 2 de produção de conhecimento' nos estudos de Ciência e Tecnologia (Bora and Hausendorf, 2004; Borrás, 2006; Jorge, 2004).

Neste contexto, os debates sobre OGM na agricultura têm vindo a incluir aspectos tão diversos

\footnotetext{
* Assistente de Investigaçāo - INIAP, Oeiras, Portugal (maa@sapo.pt; tel.: 21 4403500; fax: 21 441 6011).

* Professora Auxiliar, Dept. Engenharia Ambiente-FCT/Universidade Nova de Lisboa, Monte Caparica, Portugal.

Caso de I\&D - Investigaçāo e Desenvolvimento do INRA - Institut Nationale de la Recherche Agronomique. Ver ainda Bertrand et al., 2002.
} 
como a disseminação irreversível de transgenes no ambiente (cariz técnico); a procura de traceabilidade e informação ao consumidor (cariz ético) e reflexões sobre a utilidade real das plantas $\mathrm{GM}^{2}$ na agricultura, seu controlo por monopólios e potencial desaparecimento de variedades locais não cultivadas (cariz económico-social). A esta complexidade acresce o facto da genética ser percepcionada de modo distinto em diversas sociedades, o que Gaskell et al. (1999) relacionam com as respectivas sensibilidades culturais e factores históricos nacionais. A investigação e a tecnologia ligadas à genética têm suscitado nos cidadãos preocupações de diversos tipos verificando-se que algumas das suas aplicações são rejeitadas, constituindo objecto de estudo o grau de aceitação pública de futuras aplicações de C\&T em Eurobarómetros, alguns dos quais focam também questões sobre o papel dos peritos na definição de políticas e a importância dada ao envolvimento pessoal e público na tomada de decisões sobre $\mathrm{C} \& \mathrm{~T}^{3}$. O envolvimento de cientistas e peritos em processos de tomada de decisões de políticas públicas tem tido uma expressão crescente nas sociedades actuais, sobretudo em questões ligadas à regulação de assuntos ambientais (CNADS, 2003). Na perspectiva de Kaiser (1996), se por um lado era errado admitir que o conhecimento científico constituía o único e decisivo contributo nestes assuntos públicos, por outro lado, seria também errado negar que em muitas áreas era este conhecimento que sustentava as principais opções políticas. No entanto, Chopyak and Levesque (2002) referem como emergente um modelo de tomada de decisões que se expande além da tradicional tripla hélice constituída por 'governo-indústria-universidade' e no qual o contributo de técnicas de envolvimento e participação de cidadãos e de actores-chave resulta em melhores decisões e na capacitação aos níveis comunitário e de cidadania.

Segundo Vasconcelos (1996: p. 8), os impactos benéficos dos debates alargados que envolvem todos os actores-chave nas fases iniciais dos processos de decisão residem: “(i) numa melhoria do conhecimento sobre interesses e compromissos dos diversos actores, fazendo emergir pontos de vista inesperados; (ii) numa ajuda à evicção e/ou resolução de conflitos, criando relações e redes entre participantes com interesses variados e possivelmente conflituosos, desenvolvendo um capital social $e$ intelectual comum dificilmente atingivel de outro modo; (iii) na obtenção de uma maior diversidade de soluções, permissoras de distintas abordagens que respondem a maior gama de interesses e assuntos, aumentando a probabilidade de melhores decisões pelo alargamento do leque de opções e seu confronto com pontos de vista imprevistos; (iv) no aumento da legitimidade das decisões permitindo ainda ganhos de poder para os políticos."

Se, para uns, os processos participativos são benéficos, para outros eles têm inconvenientes que, entre outros, se reflectem em "lentidão na tomada de decisões" (Mota, 2005: p. 39). Contudo, o autor refere que os benefícios de uma participação alargada parecem suplantar os inconvenientes, de modo a que algumas instituições tendem a incorporar processos deliberativos. Os partidários do modelo de democracia deliberativa defendem que as decisões vinculativas colectivas devem, idealmente, ser tomadas na base de um processo de discussão e argumentação, no qual todas as partes eleitas (ou seus representantes) têm a oportunidade de participar e apresentar argumentos críticos a favor ou contra as propostas avançadas, tendo como objectivo principal estabelecer um processo de tomada de decisão democrático que promova um fórum livre do qual possam resultar decisões mais racionais e imparciais. Para o renascer da teoria de democracia deliberativa Ekeli (2005) cita contributos de Dryzek (1990), Rawls (1993), Habermas (1996), Gutmann e Thompson (1996).

Segundo French and Geldermann (2005: p. 378) "a maioria das decisões ambientais possui muito em comum, por exemplo, vários actores-chave, incertezas, critérios múltiplos e possivelmente conflituosos; e impactos que se prolongam no futuro", características presentes também nos contextos de decisão sobre o uso de culturas GM na agricultura e seus impactos ambientais. Sobre estes, refira-se que a DGPC 4 implementou de 2001 a 2004 o projecto Estudo de impactes de milho

\footnotetext{
2 GM - Geneticamente Modificada.

3 Ver CE, 2005 a) e b).

4 DGPC - Direcção-Geral de Protecção de Culturas.
} 
geneticamente modificado em ecossistemas agrícolas (Projecto Agro DE\&D 5 17) para colmatar a necessidade da DGPC dispor de base técnico-científica sobre o assunto para fundamentação de decisões nesse âmbito, verificando-se que, a nível Comunitário, a investigação na segurança de OGM em vários Programas-Quadro, de 1985 a 2000, envolveu 81 projectos com apoio de 70 milhões de Euros, contribuindo para um conhecimento científico útil em avaliações de risco (EC, 2001).

Contudo, a visão generalizada das culturas GM como 'anti-naturais', tem sido analisada por vários autores (Conner et al., 2003), realçando Frewer (2003) que no estudo das preocupações específicas exibidas pelos cidadãos face ao seu desenvolvimento, o recurso a metodologias de inquéritos de opinião na obtenção de dados para formulação de políticas tem como fragilidade o facto das questões colocadas puderem não reflectir as reais preocupações dos cidadãos, mas sim as que os investigadores consideram importantes. Nessa medida, admite-se que o recurso a metodologias qualitativas constitua uma mais-valia, por permitir aos participantes expressarem as suas preocupações por palavras próprias, de potencial uso posterior em inquéritos a grupos/populações representativas (Frewer, 2003). Estes testemunhos e respectiva análise permitem obter dados úteis ao mapeamento de preocupações e anseios relevantes em contextos complexos como o das culturas GM na agricultura ao qual nos dedicamos nesta investigação.

Nesta análise centrada nas preocupações dos cidadãos sobre biotecnologia na agricultura são focados aspectos ligados ao sistema agro-alimentar que assumem particular importância na actualidade, dado ter vindo a ser criticado, nos EUA, o facto de a uma crescente industrialização deste sistema se ter vindo a associar um deficit democrático, traduzido na falta de oportunidades para participação pública alargada num contexto de grande incerteza e complexidade (Hassanein, 2000). De facto, já no final da década de 1990, se considerou que o sistema de I\&D agrícola pública dos EUA e os seus eleitores seriam beneficiados pelo encorajamento de uma participação da maior gama possível de eleitores como parte integral do processo de formulação de prioridades da I\&D, dado ser considerado que esse alargamento nas decisões sobre C\&T dava um balanço melhorado entre definições de assuntos controversos como sendo puramente técnicos versus puramente sociais (Middendorf and Busch, 1997). Este último item baseia-se no reconhecimento de que todas as mudanças técnicas são também mudanças sociais (Busch 1994, cit. Middendorf and Busch, 1997), pelo que, na sua perspectiva "os cidadãos não peritos que estão envolvidos na tomada de decisões podem ver provavelmente melhor que os peritos (e ver como sendo importantes) as implicações sociais, éticas, políticas, e económicas de uma tecnologia", que por englobarem diversas escalas - do local ao global - não podem ser dissociadas da reflexão actual que decorre sobre a possibilidade dos mecanismos de regulação das sociedades operarem a nível supranacional ou transnacional.

Cravinho (2002: p. 280) afirma que "o termo escolhido para falar desta problemática foi, em inglês, 'governance', (...) em francês como 'gouvernance' e para português como governância ${ }^{6}$ (ou governação)", tema sobre o qual se debruçam outros autores (Mota, 2005; Murphy and Yanacopulos, 2005). Esta 'Era da Globalização' evidencia surgirem não só mecanismos de governância supranacionais, mas também exigências de devolução de decisões para um nível local, como sucede, com o princípio da subsidariedade "em que a UE concedeu aos países-membros autonomia para estabelecerem as suas próprias normas e calendários. Cabe aos países legislar, prorrogar a moratória ou até suspender as culturas de OGM (...)"(Schmidt, 2004: p. 98).

\section{Uma metodologia qualitativa: o "focus group"}

Para avaliar a percepção pública da biotecnologia na agricultura, foram implementados processos participativos de tipo "focus group" de acordo com a metodologia do projecto $\mathrm{PABE}^{7}$. Os trabalhos incluíram 27 pessoas das regiões de Lisboa, Sintra e Oeste, recrutadas para os "focus

\footnotetext{
5 DE\&D - Desenvolvimento Experimental e Demonstração.

${ }^{6}$ Ver Aragão (2004) e Cravinho (2002).

7 Ver Marris, C. et al. (2001), www.lancs.ac.uk/depts/ieppp/pabe/docs/pabe_finalreport.doc.
} 
group" desde Fevereiro a Dezembro de 2005 (nota 1). Estes foram organizados em três "focus group" e uma "entrevista focada", que recorre "predominantemente a questões abertas solicitando aos entrevistados questões sobre uma dada situação ou evento que seja relevante para eles e de interesse para o investigador" (Merton et al., 1956, cit. Bryman, 2001). Dois grupos foram com agricultores e actores ligados ao mundo rural e um terceiro "focus group" com cientistas/peritos, tendo estes últimos sido recrutados por convite enviado por correio electrónico, enquanto os primeiros foram recrutados por membros de Instituições Locais (Junta de Freguesia, Associação Local Leader) de modo a que representassem uma gama diversificada de perspectivas das suas comunidades.

O facilitador iniciava a sessão pedindo aos participantes que trocassem ideias acerca das evoluções nas áreas agrícola/alimentar em geral, não referindo os termos 'OGM' nem 'biotecnologia agrícola’ e, só se (e apenas) quando os participantes os referissem, isso era apontado, mas não explorado nesta fase. Aos participantes era pedida a escolha de um/dois termos ligados a agricultura e inovação para depois se criar uma lista de termos/ideias chave. A fase posterior da metodologia compreendia as seguintes etapas:

(i) O facilitador introduz o termo 'OGM' (ou um termo local apropriado) e pergunta aos participantes quais as imagens imediatas que dele têm (10 minutos);

(ii) Um pequeno 'dicionário de definições' sobre OGM é apresentado e usado para promover discussão (10 minutos). O material contém informação objectiva sobre o tema. Destacamos o recurso a folha explicativa da www. agbios.com (em Português) e/ou diagramas em acetatos (APBG, 2002) e fichas temáticas do projecto-piloto educativo apoiado pela Fundação Calouste Gulbenkian, www.institutovirtual.pt/edu-agri-biotec (Lima, 2002);

(iii) Um número específico de exemplos de OGM na agricultura é progressivamente apresentado (40 minutos) (www.institutovirtual.pt/edu-agri-biotec);

(iv) Três 'argumentos tipo' sobre OGM são apresentados (de um regulamentador, de empresa que produza OGM e de organização ambien- tal). Isto ocorre nos 30 minutos finais da discussão para explorar as percepções dos participantes sobre os 'stakeholders' (actores) mais do que para promover uma discussão sobre os vários 'argumentos tipo'.

Após cada sessão fez-se uma análise qualitativa do discurso, sendo apresentados segmentos de transcrições que evidenciem tópicos relevantes expressos pelos participantes (nota 2) no desenrolar da conversação.

\section{A percepção dos inquiridos sobe os organismos geneticamente modificados: os resultados}

Os dados obtidos nos "focus group" são consonantes com a grelha de assuntos focados em Eurobarómetros recentes ${ }^{8}$, para além de englobarem outros assuntos levantados pelos participantes. O último inquérito Eurobarómetro sobre C\&T mostrou que um 1/3 dos Europeus são hostis aos OGM, outro 1/3 é favorável e os restantes não sabem o que pensar. Perante esta divisão assume especial relevância a análise de pontos de acordo, de discórdia e de outros elementos adicionais que os participantes dos "focus group" foram capazes de expressar, nomeadamente sobre: (i) o papel dos cientistas na divulgação da ciência que fazem (CE, 2005a); (ii) o papel dos peritos na definição políticas (CE, 2005a); (iii) os riscos tecnológicos e o desejado ritmo de evolução futura, bem como as formas de regulação tecnológicas (CE, 2005a); (iv) o envolvimento pessoal na tomada de decisão sobre C\&T (CE, 2005a); (v) o envolvimento do público na tomada de decisão sobre C\&T (CE, 2005a); e (vi) o grau de aprovação de futuras aplicações de C\&T (CE, 2005b). De seguida apresentam-se os resultados de uma análise da argumentação usada pelos participantes dos "focus group", comparando-a com as conclusões de inquéritos de euro-barómetros.

\section{(i) Percepção dos peritos sobre a divulgação da informação}

Para 56\% dos Portugueses inquiridos no Eurobarómetro 224 “Os cientistas esforçam-se pouco

${ }^{8}$ Eurobarómetro 224, CE, 2005a; Eurobarómetro 225, CE, 2005b. 
em informar o público sobre o seu trabalho". Nos 25 Estados Membros europeus o valor da resposta era de 59\%(CE, 2005a: p. 87). No caso concreto da informação sobre OGM, na qual intervêm outros actores além dos cientistas, os participantes indicaram ser necessária uma melhoria da informação pública, a qual constitui um desafio dada a complexidade do assunto:

U2 (Universitário): “A minha esperança está nos jovens, porque 'burro velho não aprende linguas".

D1 (Técnico desenvolvimento rural): “(...) somos um pólo de informação, somos os primeiros a não saber muito bem!"

Outros participantes aludiram à dificuldade na passagem da informação a públicos com baixos níveis de literacia:

IN1 (Especialista, área da indústria): “(...) numa campanha que a nossa Associação, fez no Norte de Portugal, cerca de $40 \%$ dos agricultores não sabia ler!"”

IC1 (Especialista, área do consumidor): " $A$ informação científica é difícil de passar, (...) no nosso país que é especialmente iliterado!"

Para explicar o diminuto sucesso da estratégia de informação das multinacionais e da indústria, os participantes focaram a tendência para o secretismo e o uso de terminologia complexa, para além de razões de ordem contextual:

IN2 (Especialista, área da indústria): “as multinacionais começaram mal este processo, foram arrogantes (...) usaram sempre a mesma estratégia, ou seja, arranjavam um grupo de agricultores, um líder de opinião, e isto passa... as coisas correram mal, (...) coincidiram com crises, BSE, dioxinas (...)"

IN1 (Especialista, área da indústria): “(...) a indústria recorreu a critérios muito científicos e não soube passar a mensagem."

ICl (Especialista, área do consumidor): “(...) as empresas têm 'segredos'; é preciso 'tirar tudo a ferros" ".

O papel informativo da imprensa neste assunto não ficou isento de críticas, sendo evidenciada a sua parcialidade, que acaba por contribuir para a divulgação de uma informação não isenta:

U3 (Universitário): “(...) os argumentos técnicos, não é fácil passá-los (...) e mais no nosso País, isso depende muito da imprensa que é um pau de dois bicos; pode ser parte do problema ou parte da solução. A imprensa tem estado claramente mais do lado do contra." IN1 (Especialista, área da indústria): “(...) temos um problema, é o 'show-off'; só más notícias, raramente vemos as 'boas notícias?!" A2 (Agricultor): “(...) querem é o fantástico!" IN2 (Especialista, área da indústria): "Se estivesse aqui a comunicação social, era muito mais notícia os que fossem 'contra' do que os que fossem a "favor"'.

Esta parcialidade está também ilustrada nesta conversação que se reproduz:

Ol (Membro de ONG): “(...) a comunicação social não tem sido muito imparcial, umas vezes são para um lado, umas vezes para outro."

IN2 (Especialista, área da indústria): "São mais para o vosso lado, desculpe lá!"”

Ol (Membro de ONG): "Nem sempre, nem sempre."

Para os participantes a informação está polarizada, trazendo-lhes dúvidas:

V1 (Viticultor): “(...) uma pessoa não deve ouvir só uma parte. (...) devemos ter a capacidade de interrogação!".

A5 (Agricultor): “(...) quando se ouve uma vertente a falar a favor, apetece dar-lhe razão. No outro dia, ouve-se outra vertente contra e apetece dar-lhe razão!"

FLl (Técnica Produção Florestal): “(...) vem uma parte e diz uma coisa, eu não vejo mal; vem outra parte e também não vejo mal; criam-se ali dúvidas. (...) o esclarecimento está aquém das expectativas."

Por último, os aspectos de confiança em instituições científicas, da legislação e do poder económico de empresas privadas foram também focados pelos participantes, demonstrando que este assunto suscita a sua reflexão sobre diversos aspectos a ele ligados:

U3 (Universitário): "A crença em organismos científicos é maior nos EUA do que na Europa.";

IN2 (Especialista, área indústria): “(...) nenhum assunto, nenhum processo, nenhum dossier tenha sido tão legislado."

A4 (Agricultor): “(...) isto tinha que ser, não de um grupo empresarial, tinha de ser nacionalizado (...); é uma discussão interminável!" 


\section{(ii) A tensãa entre peritos e políticos na definição política}

De modo geral, é consensual a noção de que "Os políticos deviam basear-se mais nos conselhos dos cientistas peritos", conforme mostram dados do Eurobarómetro 224 já referido, onde os valores de concordância são da ordem de $64 \%$ dos Portugueses (vs. $73 \%$ de média dos 25EM). Contudo, no decurso desses processos de aconselhamento, alguns dos peritos participantes nos "focus group" que haviam sido consultados pelos políticos, identificaram alguns pontos críticos, revelando um distanciamento entre peritos e políticos:

U3 (Universitário): “(...) sempre que tenho contacto com o poder político, e já respondi perante a Assembleia da República,(...) fico preocupado com a falta de algum T.P.C. ('trabalho-para-casa') que eles não fizeram, (...), muitas vezes não leram os relatórios!"

IN1 (Especialista, área da indústria): "A nossa associação andou três anos a tentar falar com os políticos, que iam mudando, e quando já se estava encaminhado, mudava o político. E isto continua (...)."

U2 (Universitário): "Se se é político, (...) tem que se assumir responsabilidade - bem ou mal; com informação científica ou sem-, em cada altura, têm que tomar posição! (...) só tomam posições politicamente correctas (...)."

\section{(iii) Riscos tecnológicos e ritmo de evolução e regulação tecnológicas: uma percepção difusa do controlo e das compensações}

As moratórias a certas aplicações biotecnológicas têm sido vistas de modo diverso por vários cidadãos, pelo que o Eurobarómetro 224 (2005a: p. 91) avaliou o grau de concordância dos cidadãos com a afirmação "Se uma tecnologia colocar risco não totalmente compreendido, o desenvolvimento desta tecnologia deve ser parado mesmo se ela oferecer claros benefícios". Nos dados obtidos, $48 \%$ dos Portugueses era favorável a essa paragem (vs $51 \%$ de valor para $25 \mathrm{EM}$ ). Estas posições de concordância/discordância com paragens no desenvolvimento tecnológico assentam em múltiplas preocupações e visões dos contextos sociais existentes, muito relacionadas com o facto de se estar a operar num contexto de incerteza e complexidade, explicitadas nos diversos "focus group", advogando alguns participantes não haver 'risco zero':

IN2 (Especialista, área da indústria): “Quero dizer uma noção de bom senso: "não há risco zero'(...)"

IN1 (Especialista, área da indústria): “(...) advogo que "não há risco zero"".

O papel das avaliações de risco a nível laboratorial foi focado por alguns participantes, focando uns o desajuste na actualização das técnicas de análise do risco face ao ritmo veloz das inovações, e outros, a sua eficácia e transparência:

ICl (Especialista, área do consumidor): “(...) as técnicas de análise estão sempre atrasadas, sempre atrás daquilo que seria preciso."

U3 (Universitário): “(...) a FDA dos EUA fez 6000 análises (...) só para a soja GM com glifosato(...) podemos ver na internet".

Outros participantes focaram situações em que os critérios económicos vingam sobre outros, realçando potenciais consequências na ocorrência de 'asneiras':

C1 (Ex- funcionária comércio alimentar): " $O$ conceito agora é o da competitividade (...)"

Ol (Membro de ONG): "Não esperemos que as empresas se auto-limitem."

U2 (Universitário): “Os OGM (...) são uma tecnologia de futuro. (...) usada sobretudo se não se fizerem asneiras."

Apesar de cientes da ausência de riscos para a saúde pública, foi referida a preocupação pela hipótese indesejável de perda de valor de produtos tradicionais das fileiras vitícola e alimentar, a qual consideram carecer de debate mais aprofundado: U2 (Universitário): “(...) imaginemos se eventualmente se soubesse, a nível europeu, que porventura cá se fizesse vinho a partir de vinhas $G M$, lá se ia o nosso vinho como produto... do ponto de vista económico é o fim (...) Estou convencido (...) que as análises na Europa garantem que não há risco para a saúde pública, etc. Mas pode haver risco para algumas coisas. Por exemplo, (...) a introdução de milho GM em zonas (...) de milho de Avintes (...) podem vir a perder essa qualidade. E não é só para os OGM! É para todos. (...) quanto mais potente a inovação, maior o risco. Esta situação é que me aflige. Mas não se debate!".

Numa das reuniões foram referidos argumentos a favor (e contra) a existência de um fundo de 
compensações capaz de indemnizar em caso de contaminação tendo sido identificadas lacunas sobre a responsabilização a definir no âmbito desse fundo:

U2 (Universitário): “Outro problema (...) é o dos Seguros."

IN2 (Especialista, área da indústria): “Ah! Responsabilidade Civil! Não me falem disso! (...) façam como a Grécia; proíbam!" (alude a decisões da Grécia muito restritivas quanto aos OGM).

U2 (Universitário): “Mas esses seguros nada têm a ver com os riscos. Tem a ver com as contaminações de agricultores não-OGM, (...) que tem direito a pedir indemnização."

IC1 (Especialista, área do consumidor): “(...) relativamente à energia nuclear, há o seguro 'Price Anderson Act', e nunca foi conseguido um similar para o caso dos OGM."

Considerando a existência de uma desigual partilha de benefícios e riscos, onde emergem poucos benefícios para os consumidores, foi referido que:

IC1 (Especialista, área do consumidor): “Não há 'os produtos com mais sabor', 'ricos em vitaminas', que traziam vantagens aos consumidores."

U3 (Universitário): “(...) erro estratégico de marketing das empresas multinacionais que se viraram mais para a agricultura e sementes, e menos para os consumidores".

A ineficácia da biosegurança também esteve presente e foi focada na seguinte conversação:

$\mathrm{O} 1$ (Membro de ONG): “(...) um conjunto de procedimentos (...) vão sendo descurados ao ponto de termos escândalos, (...) do 'Starlink', ou o da variante do milho Bt-109, que escapou ao controlo e apareceu na Europa como Bt $-11^{10}$."

U3 (Universitário): “Concordo com esse último caso..."

IN2 (Especialista, área da indústria): “Ai, temos que concordar!"

Face ao papel da ‘informação’ e 'aceitação/ /consenso' - a curto prazo - duas visões opostas mostraram coexistir, admitindo uns que a maior informação, mais educação e ciência corresponderá a maior consenso; enquanto para outros esta relação não existirá:

Ol (Membro de ONG): "No curto prazo também não sei se mais ciência levará ao consenso".

IN3 (Especialista, área indústria): “(aludindo a maior informação, educação e ciência) vai levar a sobreponderar os conhecimentos científicos e a subponderar as componentes mais reaccionais e desinformadas".

Os participantes optimistas invocaram o que na literatura se designa por 'argumento de benefícios futuros', ao invés dos cépticos que usam 'argumentos de malefícios futuros':

IN3 (Especialista, área indústria): "Uma tecnologia emergente, assusta sempre. A sociedade tem avançado com essas rupturas. A biotecnologia encerra potencialidades enormes!"

IC1 (Especialista, área do consumidor): " $a$ controvérsia vai aumentar (...) vai levar a grandes desastres alimentares.".

\section{(iv) Envolvimento pessoal na tomada de decisão sobre C\&T}

O Eurobarómetro 224 (2005a: p. 96), ao solicitar a opinião dos cidadãos quanto à afirmação "Para pessoas como eu não é importante estar envolvido em decisões sobre C\&T", pretendeu avaliar a importância que era atribuída pelos interrogados para um envolvimento pessoal na tomada de decisão sobre C\&T. Para 60\% dos Portugueses a resposta maioritária era a não importância (vs. valor médio 25EM de 39\%). Em dois dos "focus group" realizados, as opiniões também não foram unânimes - esse envolvimento foi visto como útil por uns, mas para outros, foi considerado ineficaz: U2 (Universitário): “É preciso que haja um conjunto de pessoas que digam de forma radical NÃO aos OGM; pois é uma das formas de se conseguir as precauções mínimas."

C1 (Ex-funcionária comércio alimentar): “(...) tanto faz a gente reclamar como não..."

Al (Agricultor): "O melhor é o silêncio.(...)".

\footnotetext{
${ }^{9}$ Bt-10 - designação dada a um certo tipo (ou evento) de milho geneticamente modificado para exibir resistência a insectos mediante expressão de gene(s) de Bacillus thurigiensis.

${ }^{10} \mathrm{Bt}-11$ - designação dada a um certo tipo (ou evento) de milho geneticamente modificado para exibir resistência a insectos mediante expressão de gene(s) de Bacillus thurigiensis.
} 
Outros participantes apontaram possíveis causas para falhas de comunicação entre os diversos actores, as quais podem justificar o fraco envolvimento posterior em processos de decisão a nível nacional:

A3 (Agricultor): “O INIA (Instituto Nacional de Investigação Agrária), seria, em colaboração com a Universidade, para apoiar os técnicos que andam no terreno. Estes transmitiam os problemas e os investigadores faziam a investigação e estes técnicos aplicavam. Comparando com outros países: cá aparecem os problemas, eles (os agricultores) têm que ser científicos, ser práticos, têm que se desenrascar."

V2 (Viticultor): "Os associados são pouco unidos e debatem pouco esses assuntos".

\section{(v) Envolvimento do público na tomada de decisão sobre C\&T}

O Eurobarómetro 224 (CE, 2005a) revelou serem favoráveis as opiniões que defendiam o envolvimento do público na tomada de decisões sobre C\&T (48\% dos Portugueses vs. $58 \%$ de valor médio dos 25 EM). Nos "focus group" realizados, foi salientada a preocupação pelo fraco empenho dos Portugueses sobre assuntos de biotecnologia em geral e sobre OGM, quer a nível particular, quer institucional. Foi citada negativamente a Conferência de Consenso de Vila Flor (IACA, 2005) organizada pela Câmara Municipal de Vila Flor, com o apoio do Instituto Gulbenkian de Ciência, que visou recolher recomendações de um painel de cidadãos sobre manipulação genética de plantas, após intervenções de alguns especialistas nela participantes:

IN2 (Especialista, área indústria): “(...) fui a Vila Flor e marca uma experiência que corre mal... Era supostamente convidado um painel diversificado de especialistas (...) lamento que as entidades oficiais não tenham dado a cara.

(...) em Portugal devia ser criado um comité de biovigilância, no qual estivessem representados todos os interesses (...)".

U2 (Universitário): “Aparecem meia dúzia de pessoas que fazem barulho e o resto 'está-se nas tintas"".

Dl (Técnico desenvolvimento rural): “Mas já daqui, no âmbito dumas acções, fizemos um convite a este (alude ao auditor do ambiente do Ministério da Agricultura) e à agência de que se falou (alude à agência de segurança alimentar) e ambos não apareceram".

Outra preocupação focava a necessidade de revitalizar a "extensão rural"11, que foi "reconhecida como um mecanismo essencial de divulgação de informação e avisos, como 'um input' para uma agricultura moderna" (Jones and Garforth, 1997), e bem como a animação dos canais de comunicação com agricultores, apontando razões para inexistência de amplo debate:

Al (Agricultor): "A investigação teria de ser feita de acordo com as associações/ lagrupamentos de agricultores e o interesse geral."

A3 (Agricultor): "Está a perder-se uma tradição que eram as equipas de 'extensão'. (...) Resta haver uma discussão aberta e franca porque se a genética não se discute abertamente, isso se deve a termos políticos, económicos ou ambientais!"

\section{(vi) Grau de aprovação de futuras aplicações de C\&T}

O Eurobarómetro 225 (2005b) pediu aos cidadãos que indicassem as prioridades numa lista de 22 possíveis futuras aplicações de C\&T nos próximos 20 anos. No conjunto dos $25 \mathrm{EM}$ houve maior apoio à opção 'Proteger e reintroduzir no seu ambiente natural animais selvagens que agora estão quase extintos' e menor apoio à 'Clonagem de seres humanos de modo a que os casais possam ter um bebé mesmo quando um dos parceiros tem uma doença genética'. Entre a primeira e última (22. $\left.{ }^{\mathrm{a}}\right)$ opção, a opção de 'Desenvolvimento de culturas GM para aumentar a variedade regional de alimentos' situou-se nas menos apoiadas, em 17. a posição. Nos "focus group" alguns participantes apoiaram o 'Desenvolvimento OGM como meio de remediar a

\footnotetext{
11 A fragilidade da extensão rural foi realçada no estudo sobre a transformação da agricultura no local de Insalde, da década de 40 a 1985 (Pires e Martins, 2004: p. 44) tendo os autores demonstrado que o evoluir de técnicas agronómicas pouco reflexo teve na produção agrícola. Na actualidade algumas medidas visam contrariar esta situação, tais como os projectos de Desenvolvimento Experimental e Demonstração (DE\&D) do Programa AGRO (www.agro8-1.net).
} 
contaminação ambiental por meio biológico ('biorremediação'):

C1 (Ex-funcionária comércio alimentar): "admira-me que não se avance, (...) se estão a pensar converter minas em zonas turísticas então (...) não devem deixá-las como estão ou fazer um aterro."

E1 (Estudante universitária): “(...) podia haver um fungo que fosse consumindo o lixo..." Foi expressa a preocupação pelo não desenvolvimento nacional de inovações no domínio da biotecnologia na agricultura, e apontadas possíveis razões focando o dilema entre 'tradicional e inovador':

A3 (Agricultor): “(...) lembro-me que aqui na Estação Vieira da Natividade, de um trabalho para que os agricultores, em vez de andarem a comprar produtos para combater doenças, por ex., viroses, se comprassem plantas já isentas de vírus, e isso ficou tudo em 'águas de bacalhau'; não se percebe, no Brasil há uma política, que por motivos económicos, há produção de plantas resistentes a vírus, a fungos, para evitar a poluição com agro-tóxicos (...). E em Portugal, o que está feito? Não há investigação! Nós estamos a consumir produtos GM, não se dá é oportunidade de os agricultores beneficiarem disso. Há aí bolachinhas que são GM! De onde é que elas vêm? A PAC refere muito a agricultura biológica mas será que assim os agricultores sobrevivem (...)?"

AU1 (Técnico autárquico): “(...) as pessoas serão um bocadinho "alérgicas" à inovação".

Foi ainda realçado que as posições de aceitação/rejeição de novas aplicações da biotecnologia se devem tomar caso a caso, citando alguns participantes tendências tecnofóbicas, muito ligadas à idade sendo as populações mais jovens mais propensas a aceitar inovações ao invés das mais idosas que manifestam maior resistência:

U3 (Universitário): “(...) há exemplos de excelentes aplicações e de péssimas aplicações. (...) infelizmente vejo a maior parte das pessoas (...) a descambar para 'sou contra tudo' ou 'sou a favor de tudo'."
F1 (Formador Agrícola): “As pessoas tendem para o natural".

AUl (Técnico autárquico): “Eu não tenho problemas (...) isto tem a ver com as gerações".

$\mathrm{O}$ uso da Engenharia Genética no melhoramento de plantas foi percepcionado de forma controversa, quer como isento de problemas, quer como possuindo um cariz preocupante:

A2 (Agricultor): “(...) usar a engenharia genética para melhorar as nossas plantas não acho que seja um grande problema".

V1 (Viticultor): “(...) vi sobre isso, haver clones de vinha GM, mas ainda não há assim grande coisa. Pode ser alternativa em termos de doenças do lenho, ou de insectos. Mas é preocupante!"

\section{(vii) Outros Tópicos}

Sobre a regulamentação de zonas livres nos diplomas de coexistência ${ }^{12}$, e sua consequente legitimidade, a seguinte conversação é elucidativa da situação que existia em 2005, até ter sido publicada, a 4 de Setembro de 2006 (DRE, 2006), a portaria que estabelece as condições e o procedimento para o estabelecimento de zonas livres de culturas GM:

IN2 (Especialista, área indústria): “(...) E esta questão da coexistência, há uma recomendação."

U2 (Universitário): "Pois, uma recomendação."

IN2 (Especialista, área indústria): "Pois, acho melhor do que não haver lei, haver um vazio legal. O que não é legítimo é pedir moratórias. Nenhum País se pode legalmente opor! (...) por cá, o Algarve já se declarou livre de OGM... como se isso fosse possível!"

$\mathrm{Ol}$ (Membro de ONG): “(...) tanto é possível, que foi!"

U2 (Universitário): "Hoje, face à falta de autoridade e ao vazio legal! O problema é esse..."

Ol (Membro de ONG): "Exacto, quando o Estado se abstêm..."

IN2 (Especialista, área indústria): “O Algarve dizer que é livre de OGM é 'show-off' para a opinião pública."

\footnotetext{
12 A possibilidade de existirem repercussões das culturas GM na organização da produção agrícola levou a CE a adoptar, a 23 de Julho de 2003 , uma recomendação que estabelece orientações para a definição de estratégias e normas de boa prática nacionais para garantia da coexistência entre culturas GM e a agricultura convencional e biológica (Recomendação 2003/556/CE da Comissão sobre coexistência) de modo a que nenhuma destas formas de agricultura pudesse ser excluída na União Europeia.
} 
Ol (Membro de ONG): "É uma declaração!"

A esta situação acresce a questão da coexistência que divide os participantes:

A4 (Agricultor): "A coexistência; isso nem pensar!"

U2 (Universitário): “(...) tem que haver uma convivência dos dois tipos de produção."

Os participantes mostraram-se cientes de que a coexistência tem suscitado casos de litígio controversos:

U3 (Universitário): "Em doze anos de coexistência efectiva quantos casos houve de litígio?" IC1 (Especialista, área do consumidor): "Vários: nos EUA e no Canadá!"

U3 (Universitário): "Estatísticas oficiais que tenho e que recebo, dizem que foram zero!"

IC1 (Especialista, área do consumidor): " $N a \tilde{o}$, há vários. Relembro um caso Canadiano muito publicitado."

U3 (Universitário): “Esse até foi ao contrário! (...)"

ICl(Especialista, área do consumidor): “ $A h$, não foi, não."

U2 (Universitário): “Não! Há os tipos de casos diferentes."

U3 (Universitário): "Nesse caso ele planeou os cruzamentos entre as suas sementes e as transgénicas para obter a resistência e depois argumentou vitimizando-se. As actas do tribunal estão na internet! Ele foi apoiado nessa vitimização pelos ecologistas e até recebeu um prémio da Vandana Shiva!!".

\section{Discussão e conclusões}

De modo geral, foi possível constatar que os participantes dos "focus group"/entrevista focada foram capazes de se situar face às implicações éticas e sociais da biotecnologia independentemente do seu nível de conhecimento técnico, tendo sido possível clarificar alguns valores e preocupações face ao desenvolvimento de culturas GM no contexto agrícola nacional. Tal como notado por Marris et al. (2001), constatou-se entre os participantes dos "focus group"/entrevista focada a existência, por um lado, de uma sensação de ambivalência face ao processo de modernização da sociedade e, por outro, a constatação do desajuste das instituições sociais face aos processos rápidos e alargados de mudança social, o que é promotor de uma sensação difusa de 'ansiedade'.

\section{Esclarecimento aquém das expectativas}

A investigação indicou que os participantes consideram ser necessária uma melhoria do esclarecimento público sobre OGM, mostrando-se cientes das dificuldades envolvidas. A ideia de correlação positiva entre a informação e a aceitação desta tecnologia não foi consensual entre os participantes, admitindo alguns deles, tal como Bates et al. (2005: p. 340) referem com base em vários estudos, que "não existe uma relação directa entre ter informação, compreensão e aceitação da ciência genética" e que "uma estratégia (de disseminação) pode responder aos argumentos do público a um nível errado".

Os participantes consideraram que o esclarecimento sobre estas matérias para o cidadão comum está aquém das expectativas avaliando como insuficientes os canais de comunicação existentes entre os diversos actores ligados à I\&D na agricultura (nomeadamente entre agricultores e cientistas/investigadores) e apontando como necessária não só uma revitalização da extensão rural, defendida por Jones and Garforth (1997), como também uma adequada formação dos agricultores de culturas GM, cuja inexistência a nível nacional havia sido alvo de comentários críticos por uma participante em inquérito sobre OGM realizado em finais de 2004/início de 2005 (Lima e Vasconcelos, 2005). Além da demora na implementação de formação nesta área, iniciada a nível nacional, apenas a partir de Julho de 2005 participaram nessas acções de formação, segundo dados da DGPC (2005: p. 6), "115 técnicos de empresas de sementes, de associações de agricultores e de cooperativas. Apesar da grande adesão de várias entidades às acções de formação de formadores, durante o ano de 2005 não foram apresentadas à DGPC propostas de realização de acções de formação para agricultores", considerando o CNADS (2005: p. 29) que o seu enquadramento normativo se revelava incapaz de a assegurar eficazmente.

Alguns participantes (IN2; IN1; ICl) focaram o insucesso da estratégia de comunicação e marketing dos produtos GM pela indústria e relacionaram-no com a 'cultura de segredo', o uso de terminologia complexa, para além de razões de ordem contextual (crises BSE da e dioxinas), e ainda com a arrogância da Monsanto (Empresa multinacional 
da agroquímica), que viu a sua fama ser abalada pelo modo como erradamente calculou a reacção pública (Hagendijk, 2004). O sentimento geral expresso pelos participantes dos "focus group" foi que 'o esclarecimento está aquém das expectativas', tendo sido expresso desagrado pelo modo como os media trataram do assunto, criticando-os por terem uma abordagem 'sensacionalista' e parcial, tal como verificado por Marris et al. (2001) no contexto do projecto PABE. De facto, considera-se que a biotecnologia apresenta uma série de incertezas complexas, quer em termos científicos, quer sociais, tendo os jornalistas dificuldade no acesso a fontes e esclarecimentos que permitam uma informação adequada e tecnicamente pertinente (veja-se o mesmo fenómeno já identificado por Friedman, Dunwoody, \& Rogers, 1999, cit. Crawley, 2005). Assim, na cobertura noticiosa da biotecnologia nos EUA, foi detectada uma inclinação pró-biotecnologia com excepção de poucos episódios de notícias negativas sobre OGM gerando "uma imagem de (uma América) público tolerante aos alimentos GM..., se não entusiasta por eles, e um mundo no qual o criticismo e preocupação (está) confinado a uma mão cheia de extremistas" (Priest, 2001b, cit. Crawley, 2005: p. 11).

Os participantes dos "focus group" consideraram que a cobertura noticiosa dos OGM não era imparcial, advogando alguns inquiridos existir, para o contexto nacional, uma inclinação 'anti-OGM' (IN2), posição que foi contestada por outros (O1).

Este cariz 'anti-OGM' da imprensa escrita foi referido para Itália, por Collavin (cit. Bora and Hausendorf, 2004), tendo sido constatado que alguns sectores dos media fizeram mesmo campanhas, a ponto de ser possível "qualquer um de nós saber o que esperar de uma dada fonte noticiosa" (Gray, 2004: pp. 2-3). No contexto nacional, para alguns participantes (A3, A2, IN1) os media querem o 'fantástico' e 'dizer mal', em concordância com o que foi admitido por Conner et al. (2003) ao referirem que "parece ser tendência corrente nas sociedades ocidentais tomar mais seriamente os portadores de más notícias do que os de boas notícias. (...) aos benefícios esperados é dado menos crédito do que aos riscos temidos".

\section{Consulta a peritos e a outros actores}

O papel dos peritos na definição de políticas foi considerado, no "focus group" realizado com peritos/especialistas, preocupante, entre outras razões, devido a alguma falta de esforço de actualização por parte dos políticos sobre matérias tidas como relevantes para um eficaz processo de consulta (U3). Se por um lado, pelos participantes, foi colocada em dúvida a eficácia dos políticos em actualizar os conhecimentos nestas matérias, por outro lado, a nível nacional, havia já sido referenciada, na análise do CNADS (2005), a ineficácia de grupos de trabalho sobre OGM com peritos/especialistas que foram sendo criados e recriados e que se traduziu por poucos resultados.

Relacionado com este aspecto, Birner and Alcaraz (2004) já tinham referido com base na análise de processos participativos/debates públicos sobre genética/biotecnologia e políticas europeias (organizados em vários países e pela $\mathrm{CE}$ ), que o conhecimento científico dos peritos, por si só, não constitui uma base suficiente para escolhas políticas sobre tecnologias que envolvam risco e preocupações éticas, considerando útil integrar diferentes tipos de conhecimento nos processos de diálogo sobre políticas, incluindo várias organizações de 'stakeholders'. Este alargamento a outros actores, e a outros valores, assume crucial importância nos contextos actuais, distintos dos tradicionalmente existentes, nos quais "poderíamos esperar dos cientistas um conselho robusto em certos assuntos que ajudariam a fechar ou arrefecer debates calorosos" (Hagendijk, 2004: p. 49). Os autores referenciam que na biotecnologia se constata a existência de cientistas que surgem a favor ou contra certas posições, ou os que trilham uma via moderada mostrando bem que à trajectória desta tecnologia se aliam outros factores de decisão.

\section{Para além do risco: causas para cepticismo alargado}

Considerando a problemática dos riscos tecnológicos e do futuro ritmo de evolução e regulação desta tecnologia, vários participantes advogam não existir 'risco zero', e separam os riscos para a saúde pública e ambientais, referindo como ínfimos os primeiros e como complexos os últimos. Sobre estes, Ervin et al. (2003) referem que a reduzida base científica a partir da qual se pode compreender muitos dos riscos de biosegurança das culturas GM, argumenta a favor de uma abordagem cautelosa, o que não é razão suficiente para adiar o seu 
desenvolvimento e difusão. Alguns participantes concordaram com esta abordagem cautelosa, que segundo 'U2' não comprometerá a tecnologia dos OGM 'se não se fizerem asneiras'. Outros participantes manifestaram preocupação pelo facto de a esta abordagem cautelosa se sobreporem critérios económicos $(\mathrm{Ol} ; \mathrm{Cl})$ na senda do abordado por Marris et al. (2001), originando situações designadas por cidadãos dinamarqueses como situações de 'ganância' (Meyer and Sandoe, 2001). Uma abordagem cautelosa por parte de cidadãos portugueses foi também verificada em inquérito do OBSERVA (2003, cit. CNADS 2005), que avaliou a concordância com o ‘princípio da precaução’ ao questionar qual deveria ser a decisão das autoridades públicas (Governo e Autarquias) num contexto de incerteza face à perigosidade de produto/actividade, e que revelou serem $71 \%$ dos inquiridos favoráveis à precaução, por proibição estrita $(24,6 \%)$, ou temporária $(52,7 \%)$. Nessa inquirição foi mostrada preocupação pela desigual partilha de benefícios e riscos, com poucos benefícios para consumidores, elementos já referidos por outros autores (Burkhard, 2005; Torgersen, 2004) e com paralelo nos resultados de Marris et al. (2001).

Sobre o caso concreto das culturas GM, Ervin et al. (2003) salientam que, embora para algumas delas exista um vasto conjunto de dados científicos que indiciem riscos menores, para outras culturas obtidas e/ou em desenvolvimento, a reduzida compreensão e o vasto potencial de riscos ambientais são um desafio à instituição de melhores programas de investigação pública capazes de informar regulações de biosegurança eficazes.

Este aspecto foi focado por participantes dos "focus group" que identificaram falhas na biosegurança actual (O1; U3; IN3) citando casos descritos em relatórios oficiais (CNADS, 2005). A estas falhas liga-se a responsabilização por danos, apercebendo-se os participantes da complexidade que rodeia a sua implementação e modo de funcionamento de fundos de compensação (CNADS 2005; Hozzank, 2004; Stone, 2000) assentes em legislação específica; antevista como problemática por uns (Kershen, 2006), mas como crucial por outros, não só na biotecnologia, mas também nas ‘tecnologias convergentes' que além dela englobam a nanotecnologia, tecnologias de informação e as ciências e neurociências cognitivas (CE, 2004; Miller, 2003, Müller, 2005).
Segundo Bora and Hausendorf (2004), a evolução do debate público na biotecnologia na agricultura mostra não só uma crescente relevância dos assuntos de regulação como uma certa mudança nos conteúdos do debate em si mesmo, deixando de restringir-se a questões de biosegurança, de risco e impactes ambientais, para focar contextos político-institucionais mais alargados abrangendo questões sobre a forma "como a sociedade quer viver no futuro" (Sagar et al., 2000: p. 1). Nesta medida, as causas para um cepticismo alargado seriam múltiplas admitindo estes autores que, embora o assunto da 'confiança' continuasse a ter significado no futuro da biotecnologia, eles entendiam-no como não redutível apenas à "confiança nas instituições reguladoras", pois, para si, a confiança pública baseia-se nas percepções de como uma tecnologia pode influenciar a vida dos indivíduos, de como certas empresas/indústrias como um todo representam os interesses públicos, e do panorama sócio-político-económico subjacente às mudanças tecnológicas. A ‘confiança' e a 'desconfiança' surgiriam do discurso público dominado pelos media e organizações de activistas mobilizadores da opinião, e de esforços de governos e indústria na captação de apoio para certas visões do mundo, pelo que a 'desconfiança' como explicação, estaria em si mesma a necessitar de explicação (Hagendijk, 2004: p. 47).

\section{Isolamento vs. envolvimento - uma questão de opção?}

Nos "focus group", para alguns participantes, o envolvimento pessoal na tomada de decisão era visto como útil, mas outros optavam pelo 'isolamento’ (Al) em concordância com a sensação de alheamento e de que as decisões com consequências nos seus modos de vida eram tomadas sem eles, por instituições distantes. O papel desempenhado por um conjunto de pessoas, eventualmente associadas em ONG, foi visto como crucial (U2) como contrapeso a outras posições.

Em Portugal, de acordo com o artigo $11 .^{\circ}$ do D. L. 72/2003 (que transpõe para a legislação nacional a Dir. 2001/18/CE), decorreram recentemente dois processos de consulta pública, um durante o período de 2 de Maio a 15 de Junho de 2005, no qual foram recebidos 35 contributos escritos; e outro decorrido durante o período de 
24 de Março a 23 de Abril de 2006, no qual o número de contributos escritos recebidos foi inferior a uma dezena. Na consulta pública no âmbito de processo de avaliação de notificação para ensaios com OGM, decorrida em 2005, foram dados contributos escritos por parte de cidadãos, verificando-se que estes ficaram inacessíveis ao público pelo facto do processo ter sido suspenso, por incumprimento de resposta por parte da Empresa ao pedido de elementos adicionais feito pelo Instituto do Ambiente (autoridade competente para autorização desses ensaios). Posteriormente foi noticiada a intenção da Empresa avançar com um novo projecto de ensaios (LUSA, 2006), sobre o qual incidiu a segunda das consultas públicas. Deste modo, é o Estado que desempenha, por via das suas competências administrativas, o controlo da participação dos cidadãos neste aspecto da vida pública, sendo admitido que em situações de algum conflito o Estado por "questões de eficácia reduz a participação ao mais formal e superficial" (Esteves, 1998: pp. 221-2).

\section{Do Isolamento ao envolvimento - um percurso sinuoso?}

Foi mostrada uma preocupação pelo fraco empenho dos Portugueses em assuntos gerais, e especificamente sobre OGM e biotecnologia, tópicos sobre os quais Raffensperger (2003) considera que muitas pessoas/povos gostariam de falar por outras(os), acreditando que a todas elas(es) deveria ser dada a oportunidade de falar por si próprias(os). No entanto, a esta 'oportunidade de falar' está subjacente uma conjunção de diversos factores, cuja não ocorrência resulta ou contribui para um défice de participação. Em Portugal, entre inúmeras razões apontadas como causa deste défice, teremos "a falta de tempo e disponibilidade dos cidadãos, (...) a falta de informação em geral e a excessiva tecnicidade da informação disponibilizada, bem como a não publicitação atempada de soluções alternativas para os vários problemas colocados e a divulgação insuficiente de factos $e$ legislação, (...) determinando que, frequentemente, ele só se aperceba e actue perante factos consumados e sem uma noção clara das várias opções disponíveis." (Sá Fernandes, cit. CNADS, 2003: p. 25). Este défice de participação é particularmente sentido em questões tecnológicas, admitindo
Gonçalves (2006) faltarem oportunidades para que sobre a tecnologia/inovação um cidadão possa ser eficazmente informado, as possa compreender, e possa ter voz sobre novas escolhas tecnológicas em termos apropriados, concluindo a autora não estar a ser verdadeiramente desafiada a legitimidade tecnocrática.

Esta ideia é partilhada por Coutinho (2005), ao expressar que "a aplicação de uma tecnologia tem que ser uma decisão da sociedade". A dimensão democrática na governança dos OGM a nível da UE não está isenta de críticas (Abels, 2002) e, se para Borrás (2006) ela apresentou melhorias nalguns aspectos, permanece subdesenvolvida noutros, referindo a autora que as regulações da governança do risco em geral, e dos OGM em particular, não melhoraram a democracia participativa nos processos de tomada de decisão, nem em termos de consulta, nem de co-produção participativa de conhecimento, nem de deliberação pública. De facto, numa análise evolutiva dos modelos de participação dos cidadãos nos procedimentos de licenciamento dos OGM em diversos países Europeus, Bora and Hausendorf (2004) referem que, se antes de 1999 o seu enquadramento variava entre diversos países, existindo para uns uma participação oral directa (Alemanha, Áustria, Holanda e Luxemburgo), enquanto para outros se providenciava apenas uma participação escrita (Bélgica, Espanha, França), a situação de harmonização verificada após finais de 1999 permitiu um direccionamento para a forma de participação escrita, em detrimento das formas de participação oral.

Outras preocupações focaram o facto de, na Conferência de Consenso sobre OGM de Vila Flor (IACA, 2005), não ter sido possível assegurar a presença de um painel representativo de todos os interesses/actores e a necessidade de revitalizar a 'extensão rural', apontando-se falhas de comunicação entre agricultores, cientistas e investigadores.

\section{'Tradição' e 'Inovação' - as facetas territoriais e culturais}

Relacionado com o grau de aprovação de futuras aplicações de C\&T, foi referido, por um lado, o dilema entre a 'tradição e inovação'. À semelhança dos resultados obtidos por Marris et al. (2001), os participantes nos "focus group" 
mostraram estar cientes da incerteza quanto às consequências a longo prazo dos OGM e preocupados com o ritmo veloz da inovação alimentar e alimentos GM. Outros participantes consideraram que alguns cientistas na actualidade, e ao invés dos 'cientistas de outrora', não eram independentes dos interesses económicos, mostrando acreditar não se poder, nem se dever, esperar que as empresas se auto-limitem ou tenham como prioridade o bem-estar social e a protecção ambiental, atribuindo às $\mathrm{ONG}$, entre outros possíveis actores, a defesa destes assuntos ligados ao bem comum, que na agricultura se podem focar no tema da paisagem e território agrícola, ao qual se associa a questão actual da coexistência entre culturas GM e convencionais.

$\mathrm{Na}$ medida em que a paisagem agrícola depende de determinismos biofísicos ou ecológicos, económicos e sociais, são mobilizados diversos actores que animam "debates entre os poderes públicos, os grupos sociais e os cientistas em torno de questões fundamentais como a protecção das culturas (...), entre outras" (Cary, 1997: p. 62). Deste modo, foi expressa preocupação pelo desenvolvimento de culturas GM em fileiras nas quais o cariz histórico-cultural dos produtos tradicionais possa ser posto em causa, como no caso dos vinhos e fileira vitícola que têm como património cultural da UNESCO para Portugal a 'Paisagem da Cultura da Vinha do Pico', em 2004 e o 'Alto Douro Vinhateiro’, em 2001 (Canelas, 2004). Estes anseios são, portanto, compreensíveis, se atendermos ao facto de ser enfatizado que "o interesse pelos problemas da paisagem e do ambiente assume maior relevância nas sociedades com uma componente cultural forte" (Cary, 1997: p. 62) o que sucede em Portugal, relativamente a algumas fileiras agrícolas.

Os participantes expressaram preocupação pelo não desenvolvimento a nível nacional de produtos GM, que depois são importados (IN2; A3), tendo citado a experiência Brasileira, em oposição à situação nacional e comunitária que foi por eles considerada como favorecedora da agricultura biológica em detrimento de outros tipos de agricultura. Esta conjuntura foi analisada por Amine (2003: pp. 383-4), que realçou o facto de, em 2001, os ministros da agricultura da UE terem respondido aos receios dos Europeus sobre segurança alimentar (OGM, BSE, entre outros) com a 'Declaração de Copenhaga', criando um plano de acção de desen- volvimento da agricultura biológica visto como uma oportunidade de negócio e como factor de competitividade para os produtores europeus. Sobre o grau de aprovação de futuras aplicações de C\&T, verificou-se que alguns participantes apoiavam os OGM para descontaminação ambiental (C1; E1), enquanto outros as viam como eminentemente preocupantes (V1) aludindo aos seus potenciais impactes ecológicos, na linha da visão descrita por Hughes (2005: p. 258) como sendo 'a visão dos OGM como poluentes', a qual suscitaria incapacidade pública para o seu plantio. Aos OGM também se associa, por vezes, a noção de 'antinatural' (Deckers, 2005: p. 451), que foi invocada por participantes de "focus group" realizados no âmbito do projecto PABE (Marris et al., 2001: p. 67).

\section{Duas visões opostas}

A retórica optimista, no actual contexto de críticas aos OGM na agricultura, designada por Burkhard (2005) como 'argumento de benefícios futuros', foi adoptada no discurso de um participante (IN3). A esta posição contrapôs-se a de outro participante (ICl), focando eventuais danos ambientais irreversíveis (tal como referiram Myhr and Traavik, 2002) e prevendo como interminável a controvérsia sobre OGM.

A título conclusivo, refira-se que a implementação destes "focus group" sobre inovação e biotecnologia na agricultura constituiu, tanto quanto sabemos, um processo pioneiro a nível nacional, na medida em que foi gerada uma oportunidade de participação oral, que possibilitou clarificar alguns aspectos importantes do debate sobre esta matéria na sociedade portuguesa, num momento em que, contudo, surge um alerta para o facto de que "se de modo geral existe uma tendência para um maior envolvimento público, parece também ser claro que o pêndulo possa virar de novo no sentido oposto" (Hagendijk, 2005: p. 59). A participação social em assuntos controversos é essencial apesar de existir uma diminuição gradual da importância dada ao envolvimento público em recentes documentos oficiais da União Europeia, pelo que a sua promoção continuará a ser um desafio nas sociedades actuais.

Nota 1 - Integrados no projecto 'Cidadania ambiental: acções educativas e processos partici- 
pativos sobre inovações na agricultura' (Org.: LPN; Apoio: IA) e decorridos a: 2005/02/15 (Sintra, 7 cidadãos meio rural); 2005/04/15 (Lisboa, 8 peritos com formação específica diversa); 2005/11/22 (Cadaval, 8 cidadãos meio rural). Devido a pouca disponibilidade de tempo dos participantes, a 2005/12/16 decorreu uma entrevista focada (Óbidos, 4 cidadãos meio rural) com plano similar aos dos "focus group".

Nota 2 - Aos participantes dos "focus group" (fgl, fg2, fg3)/entrevista focada (ef) foram atribuídos códigos correspondentes a: A1 a A5 Agricultores (Agro-pecuária, Frutícolas e Hortí- colas; A1 do fgl; A2-A5 do fg3); AU1 - Técnico Autárquico (ef); C1- Ex-funcionária Comércio Alimentar (fgl); Dl - Técnico Desenvolvimento Rural (fg3); El - Estudante Universitária (fgl); Fl - Formador Agrícola (fg3); FLl - Técnica Produção Florestal (fg3); IC1 - Especialista Instituto Consumidor (fg2); IN1 a IN3 - Especialistas Membros Indústrias(fg2): IN1 - Protecção Plantas, IN2 - Nutrição Animal, IN3 - Agroquímica; Ol - Membro Plataforma Transgénicos Fora Prato (várias ONG anti-OGM; fg2); U1 a U3 - Universitários/Cientistas (fg2); V1 e V2 - Viticultores (ef). 


\section{Bibliografia}

ABELS, G., 2002, Experts, Citizens, and Eurocrats - towards a Policy Shift in the governance of Biopolitics in European Integration Online Papers 6(19) < http://eiop.or.at/eiop/texte/ 2002-019a.htm>

AGROPORTAl, 2006, Transgénicos: Bruxelas pode recusar portaria Portuguesa sobre municípios livres, <www.agroportal. pt $>(2006 / 05 / 17)$

AMINE, L. S., 2003, "An integrated micro - and macrolevel discussion of global green issues: 'It isn't easy being green", Journal of International Management, 9, 373-393.

APBG, 2002, Association des Professeurs de Biologie Géologie: Biotechnologies, des sciences pour la vie. Complément au Bulletin Biologie Géologie n. ${ }^{\circ}$ 4-10, France.

ARAGÃO, A. (2004), "A Governância na Constituição Europeia: Uma Oportunidade Perdida?", Studia Juridica, 84, 106-121. Coimbra Editora, Coimbra.

BATES, B. R., Lynch, J. A., Bevan, J. L. and Condit, C. M., 2005, "Warranted concerns, warranted outlooks: a focus group study of public understandings of genetic research", Social Science \& Medicine, 60, 331-344.

BECK, U., 1992 [1986], Risk Society, Londres, Sage Publications.

BERTRAND, A., Marris, C. et Joly, P.-B., 2002, "Co-construction d'un programme de recherche: une expérience pilote sur les vignes transgéniques. Méthodologie pour l'élaboration d'un dispositif de co-construction", INRA-STEPE Report, France, INRA.

BIRNER, R. and Alcaraz, G., 2004, "Policy on Genetically Modified Crops in Europe: Insights for African Policy Dialogues on Biotechnology", DRAFT 2nd Session African Policy Dialogues on Biotechnology, Southern Africa/ Zimbabwe.

BORA, A. and Hausendorf, H., 2004, "PARADYS - Participation and the Dynamics of Social Positioning", Final Report to the European Comission, Bielefeld and Bayreuth. $<$ www.uni-bielefeld.de/iwt/paradys $>$

BORCH, K. and Rasmussen, B., 2005, "Refining the debate on GM crops using technological foresight - the Danish experience", Technological Forecasting \& Social Change, 72, $549-566$

BORRÁS, S., 2006, "Legitimate governance of risk at the EU level? The case of genetically modified organisms", Technological Forecasting \& Social Change, 73, 61-75.

BRYMAN, A., 2001, "Social Research Methods", Oxford, Oxford Press.

BURKHARD, J., 2005, "Agricultural Biotechnology and the Future Benefits Argument", Journal of Agricultural and Environmental Ethics, 14, 135-145.

CANELAS, L., 2004, "Vinhas da Ilha do Pico foram eleitas património mundial com enorme apoio", Público, 2004/07/ /03, 40 .

CARY, F. C., 1997, "Paisagem e Agricultura" in Cancela de Abreu (org.), Paisagem, Lisboa, DGOTDU, 47-66.
CE, 2004, CTEKS Convergent Technologies for a European Knowledge Society. Conference Report from the high level expert group on 'Foresighting the New Technology Wave', Luxemburgo, Comissão Europeia.

CE, 2005a, Eurobarómetro Especial 224/63.1 - TNS Opinião \& Valores Sociais, Luxemburgo, Comissão Europeia. <http:/ /europa.eu.int/comm/public_opinion/archives/ebs/ebs 224 report_en.pdf $>$

CE, 2005b, Eurobarómetro Especial 225 - Social values, Science \& Technology, Luxemburgo, Comissão Europeia. <http://europa.eu.int/comm/public_opinion/archives/ebs/ ebs_225_report_en.pdf $>$

CHOPYAK, J. and Levesque, P., 2002, "Public participation in science and technology decision making: trends for the future", Technology in Society, 24, 155-166.

CIB, 2005, Comunicado de Imprensa 'CIB comenta regulamentação pelo Governo do cultivo de milho transgénico em Portugal'.

<http://www.cib.biotecnologia.com.pt/pics/CI 050422 CConf_Regulamentacao-CMinistros.pdf $>$

CNADS, 2003, Reflexão sobre o Acesso à Informação, a Participação Pública nos Processos de Tomada de Decisão e o Acesso à Justiça, Lisboa, Fundação Calouste Gulbenkian.

CNADS, 2005, Parecer do CNADS sobre os Organismos Geneticamente Modificados, Lisboa, CNADS.

CONNER, A. J.; Glare, T. R. and Nap, J. P., 2003, "GM SPECIAL ISSUE - The release of genetically modified crops into the environment, Part II. Overview of ecological risk assessment", The Plant Journal, 33, 19-46.

COUTINHO, A., 2005, Público, 2005/12/05 (e entrevista RTP2, 2005/12/04)

CRAWLEY, C.E., 2005, Framing the Genetic Engineering Debate: An Examination of Frames and Sources in Local Newspaper Reporting, PhD Dissertation, Knoxville, The University of Tennessee.

CRAVINHO, J. G., 2002, Visões do mundo. As Relações Internacionais e o Mundo Contemporâneo, Lisboa, ICS.

DECKERS, J., 2005, “Are Scientists Right And Non-Scientists Wrong? Reflections on Discussions of GM", J. of Agricultural and Environmental Ethics, 18, 451-78.

DGPC, 2005, “Coexistência Entre Culturas Geneticamente Modificadas e Outros Modos de Produção. Relatório de Acompanhamento", 46p, Oeiras.

< www.cibpt.org/docs/2005DGPCRelatOGM.pdf>

DRE, 2006, Portaria 904/2006, Diário da República n. ${ }^{\circ} 170$, Série I, Portaria conjunta do Ministério da Agricultura Desenvolvimento Rural e Pescas (MADRP) e do Ministério do Ambiente, Ordenamento do Território e Desenvolvimento Regional (MAOTDR), que estabelece as condições e o procedimento para o estabelecimento de zonas livres de culturas geneticamente modificadas. <www.dre.pt>

ERVIN, D. E. et al., 2003, "Towards an ecological systems approach in public research for environmental regulation of 
transgenic crops", Agriculture, Ecosystems and Environment, 99, 1-14.

ESTEVES, J. P., 1998, A Ética da Comunicação e os Media Modernos. Legitimidade e Poder nas Sociedades Complexas, Lisboa, Fundação Calouste Gulbenkian/JNICT.

FRENCH, S. and Geldermann, J., 2005, "The varied contexts of environmental decision problems and their implications for decision support", Environmental Science \& Policy, 8, 378-391.

FREWER, L. J., 2003, "Societal issues and public attitudes towards genetically modified foods", Trends in Food Science \&Technology, 14, 319-332.

GASKELL, G., Bauer, M. W., Durant, J. and Allum, N. C., 1999, "Worlds apart? The reception of genetically modified foods in Europe and the US", Science, 285, 384-387.

GONÇALVES, M. E., 2006, "Risk and the governance of innovation in Europe: An introduction", Technological Forecasting \& Social Change, 73, 1-12.

GRAY, A. J., 2004, "Ecology and government policies: the GM crop debate", Journal of Applied Ecology, 41 (1), 1-10.

JONES, G. E. and Garforth, C., 1997, "The history, development, and future of agricultural extension", in Swanson, B. E. et al. (orgs.), Improving Agricultural Extension. A Reference Manual, Rome, FAO.

HAGENDIJK, R., 2004, "The Public Understanding Of Science and Public Participation In Regulated Worlds", Minerva, 42, 41-59.

HAGENDIJK, R., 2005, "Science Shops and Civic Sciences after 'Lisbon"”, in ISSNET/ Steinhaus, N., (orgs.), Proc. of the 2nd International Living Knowledge Conference 'Advancing Science and Society Interactions', Bonn, ISSNET/ Steinhaus, N. Ed., 56-64.

HASSANEIN, N., 2000, "Democratizing Agricultural Knowledge Through Sustainable Farming Networks" in Kleinman, D.L. (org.)., Science, Technology \& Democracy, NY, State Univ. of New York Press.

HENDRIKS, C. M., 2005, "Participatory storylines and their influence on deliberative forums", Policy Sciences, 38, 1-20.

HOZZANK, A., 2004, "Sustainable Agricultural Systems and GMOs. Is Co-Existence Possible?" in Challenges and Risks of Genetically Engineered Organisms, Paris, OCDE, 161-170.

HUGHES, E., 2005, "The contaminated risk of GM crops: natio-nalism and the genetic modification debate", Journal of Public Affairs, 5, 251-262.

IACA, 2005, "Conferência de Consenso sobre OGM", Alimentação Animal, 51, 71.

JORGE, M. M. A., 2004, "Ciência, Sociedade e Ambiente. A transdisciplinariedade como desafio epistemológico", Educação, Sociedade \& Culturas, 21, 23-50.

KAISER, M., 1996, “Toward more secrecy in science? Comments on some structural changes in science - and on their implications for an ethics of science", Perspectives on Science, 4(2), 207-230.
KERSHEN, D. L., 2006, "Proposed Liability Legislation for Transgenic Crops", ABA Agricultural Management Comm. Newsletter, 10(2), 7-11.

LIMA, M. A. A., 2002, Conjunto de fichas didácticas de genética e biotecnologia vegetal < $<w w$.institutovirtual.pt/edu-agribiotec $>$

LIMA, M. A. A. and Vasconcelos, L., 2005, "One Step Further: young student's perceptions on plant biotechnology and their ethical reasoning about S\&T in shaping adult visioning", in The Lisbon Workshop on BIOTECH AGE Abstract Book, Lisboa, Dinâmia/ISCTE, p. 12.

LUSA, 2006, "Transgénicos: Empresa que quer realizar ensaios com milho apresenta novo projecto", Notícia de Torres Vedras, Lusa (online), 2006/02/06.

MARRIS, C. et al., 2001, Public Perceptions of Agricultural Biotechnologies in Europe Final Report of PABE research project. Lancaster. <www.lancs.ac.uk/depts/ieppp/pabe/docs/ pabe_finalreport.doc $>$

MEYER, G. and Sandøe, P., 2001, Report of Project 'Dialogue on biotechnology in relation to plants', <www.bioethics. kvl.dk>

MIDDENDORF, G. and Busch, L., 1997, "Inquiry for the public good: Democratic participation in agricultural research", Agriculture and Human Values 14, 45-57.

MILLER, S., 2003, "Converging Technologies: Innovation, Legal Risks, and Society", Risk Management Newsletter, 1(3).

MOTA, A., 2005, Governo Local, Participação e cidadania. O caso da área metropolitana de Lisboa, Lisboa, Nova Vega.

MÜLLER, B., 2005, Personal statement for FAO Electronic Forum on Biotechnology in Food and Agriculture (14/02/ 2005), <www.fao.org/biotech/forum.asp>

MURPHY, J. and Yanacopulos, H., 2005, "Understanding governance and networks: EU-US interactions and the regulation of genetically modified organisms", Geoforum, 36, 593-606.

MYHR, A. and Traavik, T., 2002, "The Precautionary Principle: Scientific Uncertainty and Omitted Research in the Context of GMO Use and Release", J. of Agricultural and Environmental Ethics, 15, 73-86.

PIRES, C. B. e Martins, V. C., 2004, A transformação da agricultura de Insalde - Paredes de Coura. Da década de 40 a 1985, Braga, Empresa Gráfica do Norte.

PTFP, 2005, "Comunicado Imprensa - Plataforma Transgénicos Fora Prato - Providência Cautelar interposta pelo Advogado José Sá Fernandes - Associações pretendem parar Transgénicos em Portugal”, 2005/04/20.

PTFP, 2006, "Comunicado Imprensa - Transgénicos Fora das Áreas Protegidas", 2006/05/22.

RAFFENSPERGEr, C., 2003, “The Precautionary Principle: Making Wise Decisions in an Uncertain World", in NABC Report 15, Biotechnology: Science and Society at a Crossroad, NY, NABC Ed, 181-190.

SAGAR, A., Daemmrich, A. and Ashiya, M., 2000, "The tragedy of the commoners: biotechnology and its publics", Nature Biotechnology, 18, 2-4. 
SCHMIDT, L., 2004, "Lei transgénica", Expresso/Única, 2004/12/11, 99-100.

STONE, J. M., 2000, "Restraints on Competition through the Alteration of the Environment at the Genetic Level", New York Univ. Envtl. Law Journal, 8(3), 704-32.
TORGERSEN, H., 2004, "Lessons from the past of biotech in Europe". < www.oeaw.ac.at/ita/ebene5/HTPruhoshort.pdf> VASCONCELOS, L., 1996, The Use of Information and Interactive Processes in Growth. Management. The Case of the New Bridge Controversy, PhD Dissertation, Lisboa, FCT/ /Universidade Nova de Lisboa. 